\title{
Rôle du coton sur la filière maïs au Burkina Faso
}

\section{Aurore Guenot et Marilyne Huchet-Bourdon}

\section{Q OpenEdition \\ Journals}

Édition électronique

URL : http://journals.openedition.org/economierurale/4353

DOI : $10.4000 /$ economierurale.4353

ISSN : 2105-2581

Éditeur

Société Française d'Économie Rurale (SFER)

\section{Édition imprimée}

Date de publication : 15 mai 2014

Pagination : 107-119

ISSN : 0013-0559

\section{Référence électronique}

Aurore Guenot et Marilyne Huchet-Bourdon, "Rôle du coton sur la filière maïs au Burkina Faso », Économie rurale [En ligne], 341 | mai-juin 2014, mis en ligne le 15 mai 2016, consulté le 01 mai 2019. URL : http://journals.openedition.org/economierurale/4353 ; DOI : 10.4000/economierurale.4353 


\section{FAITS ET CHIFFRES}

\section{Rôle du coton sur la filière maïs au Burkina Faso}

Aurore GUENOT • Marilyne HUCHET-BOURDON • AGROCAMPUS OUEST, INRA, UMR1302, Rennes marilyne.huchet-bourdon@agrocampus-ouest.fr

L'objectif de ce papier est de déterminer, à partir d'une enquête menée sur 98 exploitations agricoles, les facteurs de développement de culture du maïs au Burkina Faso et notamment l'influence du système coton sur cette production de maïs. Deux régions caractérisées par un système coton différent, la zone Ouest et la Sissili, sont analysées.

'agriculture burkinabé représente plus de $30 \%$ du PIB du pays et occupe 84,5\% de la population active ${ }^{1}$. Il s'agit avant tout d'une agriculture de subsistance basée sur les céréales (sorgho, mil, maïs, riz et fonio). Concernant les cultures de rente, la filière coton représente $21 \%$ de la valeur ajoutée du secteur agricole, réalise $60 \%$ des exportations et emploie plus de 3 millions de personnes. Au cours des 40 dernières années, le système coton a joué un rôle significatif dans l'évolution du panorama agricole et a été un exemple en matière d'organisation et de structuration de filière. Ce système intégré a permis aux agriculteurs burkinabés d'accéder à des moyens de production modernes dédiés à cette culture de rente tout en incitant le maiis en tant que culture vivrière dans les assolements, favorisant la sécurité alimentaire des agriculteurs.

\section{La structuration de l'agriculture burkinabé L'influence du " système coton »}

Le « système coton » qui émerge dans les années 1970 repose sur la notion de filière intégrée avec la Société burkinabé des fibres textiles (SOFITEX), société para-étatique ayant alors le monopole des opérations d'achat de la matière première aux paysans, d'égrenage, de commercialisation du cotonfibre et des graines de coton. Néanmoins,

1. Recensement général de la population et de l'habitat 2006-2010, Burkina Faso. la SOFITEX, ainsi que les autres sociétés cotonnières ouest-africaines, encouragent également la culture du maïs en rotation avec le coton (Fusillier, 1994) ${ }^{2}$. Le but est d'accompagner le développement de la filière maïs qui présente des enjeux en termes de commercialisation à l'échelle locale et régionale tout en permettant également d'assurer la sécurité alimentaire des producteurs (Freud, 1999) ${ }^{3}$. Comme la majeure partie des cultures vivrières africaines, la filière maïs n'est pas organisée : filière éclatée avec une multitude d'acteurs (producteurs, transformateurs, commerçants), un secteur informel important, une faiblesse des organisations professionnelles, une délimitation spatiale floue et un encadrement par le secteur public quasiment inexistant (MAE, $2001)^{4}$. La structuration de la filière coton se poursuit, quant à elle, avec la création en

2. Fusillier J.-L. (1994). Bilan et perspectives de diffusion de la maïsiculture en zone de savane d'Afrique de 1'Ouest. Extrait de Production et valorisation $d u$ maïs à l'échelon villageois en Afrique de l'Ouest, Actes du colloque «Maïs prospère » 25-28 janvier, Cotonou, Bénin.

3. Freud H.-E. (1999). Au Burkina Faso, les céréales traditionnelles peuvent devenir des cultures de rente. CIRAD, Montpellier, $116 \mathrm{p}$.

4. Ministère des Affaires étrangères (2001). Filières agro-alimentaires en Afrique : comment rendre le marché plus efficace ? Direction générale de la coopération internationale et du développement, étude réalisée par le CIRAD, coordonnée par Michel Griffon. 
1998 de l'Union nationale des producteurs de coton (UNPCB) qui fédère l'ensemble des Groupements de producteurs de coton.

\section{L'accès aux moyens de production}

Les deux cultures, vivrière et de rente, entrent en concurrence en matière d'accès aux moyens de production (main-d'œuvre et engrais notamment). Ainsi, lorsque le prix du coton baisse, les engrais distribués par la SOFITEX sont partiellement détournés au profit d'autres cultures plus rémunératrices telles que le maïs ou l'arachide ou au profit de cultures vivrières telles que le mil et le sorgho. Les surfaces en coton sont ainsi progressivement réduites au profit des cultures d'arachide et de céréales.

\section{Une forte variabilité des prix des intrants et du prix d'achat du coton}

Les années 1990 sont marquées par des changements politiques et macroéconomiques affectant le système coton et l'agriculture burkinabé. D'une part, le prix du coton payé au producteur chute sous l'effet de la réforme de la filière coton par le Programme d'ajustement sectoriel agricole sous l'égide des institutions de Bretton Woods. D'autre part, du fait de la libéralisation du marché des céréales, les contrats passés sur le maïs avec les Grands Moulins du Burkina (GMB) et les brasseries sont rompus (Schwartz, 1997 ; Kaminsky, 2007) ${ }^{5}$. Dans les années 2000, la crise de la filière coton se poursuit au Burkina Faso. Elle est marquée au cours de la campagne 2007-08 par la chute de

5. Schwartz A. (1997). Des temps anciens à la dévaluation du franc C.F A., les tribulations de la culture du coton au Burkina Faso. Annales Géographie n`595, Paris, Armand Colin, p. 288-312 ; Kaminsky J. (2007). Réforme de la filière cotonnière burkinabé : retour sur dix ans de mutation. Analyse des impacts économiques et sociaux sur les producteurs et implication des organisations agricoles. Rapport FARM, 234 p. la production ${ }^{6}$ résultant notamment de la hausse du prix des intrants, de la baisse annoncée en début de campagne du prix d'achat aux producteurs (fixé à FCFA 145/ $\mathrm{kg}$ en 2007-08 contre FCFA 165/kg en 20062007) et des conditions climatiques particulièrement défavorables (pluies tardives, puis inondations ponctuelles). La filière maïs s'avère alors plus rémunératrice, mais est néanmoins risquée étant donné les prix très fluctuants de la matière brute et la difficile répercussion sur les prix de vente des produits transformés. En 2006, le prix d'achat du maïs s'élevait à FCFA $85 / \mathrm{kg}$ alors qu'il est de FCFA 170/kg en moyenne en 2009.

Dans ce contexte, l'objectif de ce papier est d'identifier les facteurs de développement d'une culture vivrière, le maïs, en présence d'une culture de rente, le coton, au Burkina Faso en notant toutefois que le maïs fait l'objet d'une commercialisation à l'échelle locale et dépasse ainsi la notion de culture vivrière stricte. La filière coton peut-elle avoir un effet d'entraînement dans la structuration et l'émergence d'une filière maïs organisée ? Cette question est d'autant plus pertinente suite à la crise alimentaire de 2008 qui a frappé l'économie mondiale et compte tenu des enjeux en matière de sécurité alimentaire mondiale. Afin d'éclairer les décideurs sur les facteurs déterminant l'orientation vers ces cultures au Burkina Faso, des enquêtes ont été menées auprès de 98 exploitations agricoles réparties sur deux zones, l'une située au cœur de la zone cotonnière et fortement influencée par le système coton, l'autre située en périphérie.

\section{La relation entre système coton et filière maïs}

Après une période d'évolution concomitante des surfaces de coton et maïs durant

6. De 650000 tonnes lors de la campagne 20062007 à 363000 tonnes en 2007-2008. Géocoton (2009). Évolution de la production par pays. Document interne, $8 \mathrm{p}$. 
la seconde moitié des années 1990, les surfaces de maïs connaissent une évolution croissante au cours de la décennie 2000 (figure 1). Notons que les surfaces en coton connaissent une baisse importante après 2007 alors que les surfaces en maïs ne cessent de croître. Ainsi, l'évolution des surfaces fait clairement apparaître la rotation coton/maïs. Après des fluctuations et des années basses entre 2003 et 2005, les rendements du maïs enregistrent une forte augmentation et décrochent par rapport aux rendements du coton restés relativement stables sur la période 1995-2005 avec une moyenne de 1,08 t/ha (figure 2). L'évolution comparée des rendements souligne notamment le jeu de répartition des engrais chimiques sur l'une ou l'autre des cultures. Compte tenu de la situation difficile de la filière coton en 2007 et bien que les intrants distribués par la SOFITEX étaient destinés au coton, les producteurs ont massivement détourné ces engrais vers les céréales ou bien les ont revendus sur le marché. Par ailleurs, Bricas et al. (2009) ${ }^{7}$ notent que l'introduction de variétés plus performantes et mieux adaptées à la sécheresse a également participé à une augmentation des rendements du maïs.

Figure 1. Surfaces (ha)

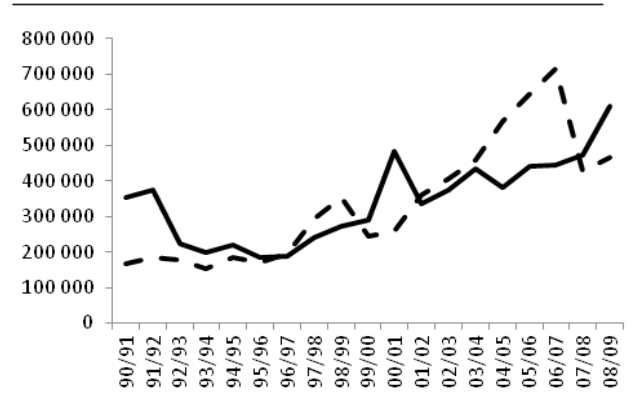

\section{Méthodologie de l'enquête et caractéristiques des zones de l'étude}

L'enquête menée auprès de 98 exploitations agricoles constitue le cœur de ce travail. Une description précise de la méthodologie d'enquête et de l'échantillonnage est présentée en annexe. La méthode retenue consiste notamment à comparer deux zones, la zone Ouest et la Sissili (figure 3). Ces deux zones ont été choisies compte tenu du poids différent du coton afin de comparer son impact sur les autres cultures et notamment celle du maïs. La Sissili est une province du Burkina Faso où le système de culture est basé sur le maïs, les tubercules et le coton. La zone Ouest comprend les provinces du Houet et de la Comoé. Dans la province du Houet, située dans l'ancien bassin cotonnier, coton et maïs sont les deux cultures majeures. La Comoé, nouveau bassin cotonnier, est caractérisée par un système de cultures maïs/ riz/fruits/coton.

Ces deux zones ont également été retenues en raison d'un facteur commun qu'est la présence d'une Organisation de producteurs $(\mathrm{OP})$. L'UNPCB est très
Figure 2. Rendements (Kg/ha)

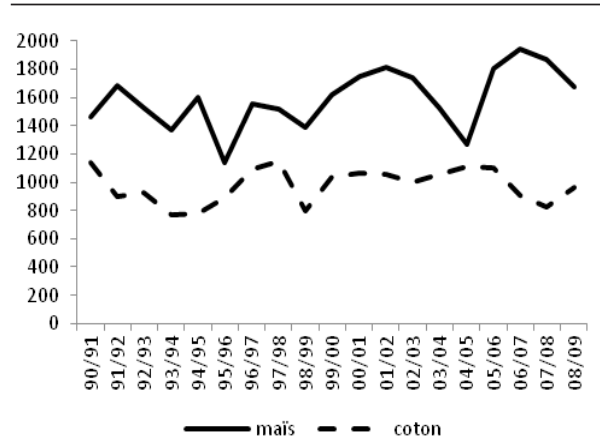

Sources : bases de données Agristat, Faostat (2009) ; Sofitex (2009).8.

7. Bricas N., Thirion M.-C., Zoungrana B. (2009). Bassins de production et de consommation des cultures vivrières en Afrique de l'Ouest et $d u$ Centre. Rapport provisoire, $51 \mathrm{p}$.
8. Agristat (2009). Statistiques sur l'Agriculture et l'Alimentation du Burkina Faso. 
Figure 3. Localisation des zones et des régions de l'étude

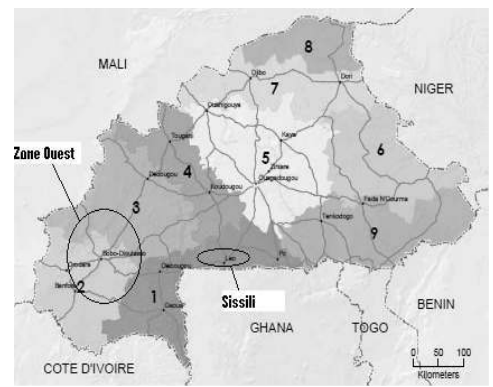

Source : FEWS NET Burkina Faso, avril 2009. Bulletin sur la situation alimentaire.

présente dans la zone Ouest tandis qu'elle est peu implantée en Sissili. Dans cette zone en effet, la Fédération des producteurs professionnels de la Sissili (FEPPASI) est l'Organisation de producteurs dominante.

Afin d'illustrer les différentes caractéristiques de ces deux zones, les figures 4 (4a-4d) représentent l'évolution de la production et des surfaces en coton et maïs dans deux vastes régions auxquelles elles appartiennent : la région des Hauts bassins (incluant la zone Ouest) et la région Centre Ouest (incluant la province de Sissili) respectivement (figure 3).

Dans la région des Hauts Bassins (zone Ouest), la figure $4 b$ met en évidence un décrochage entre une stagnation des surfaces en maïs depuis 2001-02 et des surfaces coton qui augmentent. La hausse des productions depuis 2004 suggère toutefois une productivité accrue du maïs (figure 4a).

En région Centre Ouest (Sissili), l'augmentation des productions semble être en étroite corrélation avec l'augmentation des surfaces, avec toutefois un potentiel de rendement plus important pour le maïs. Il existe ainsi un léger processus d'intensification pour la culture du maïs (figures $4 c$ et $4 d$ ).

Figure 4. Production et surface en régions Hauts Bassins (zone Ouest) et Centre Ouest (Sissili)

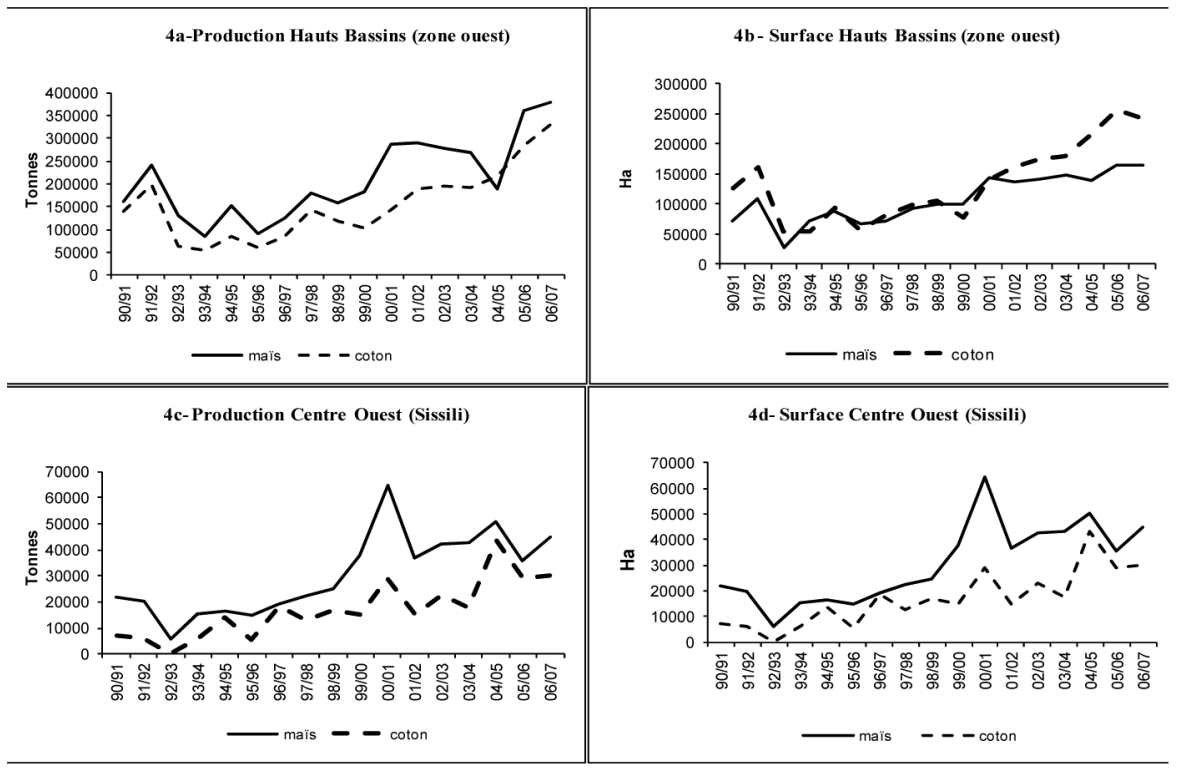

Source : les auteures à partir de la base de données Agristat (2009). 
Déterminants microéconomiques de I'orientation de la production de coton et de maïs

\section{Des facteurs techniques et sociaux concourent aux choix d'assolement des producteurs}

Avec une moyenne de 5,9 ha, le coton représente $51 \%$ de la surface totale moyenne des Unités de production agricole (UPA) en zone Ouest (figure 5a). Le maïs occupe le second poste avec $28 \%$ de la surface en moyenne. En Sissili, d'après la figure $5 b$, le maïs occupe le premier poste dans l'assolement (35\%). Sorgho rouge, coton et arachide sont présents à hauteur de 10 à $12 \%$ et le reste se décompose à parts égales entre protéagineux et oléagineux.

Les caractéristiques et contraintes agroécologiques présentent de fortes similitudes et les deux zones sont dotées de sols aptes aux cultures pluviales, mais de nature érosive et sont fortement carencés en matière organique (tableau 1). L'appareil de production des exploitations de la zone Ouest est plus moderne qu'en Sissili et la possession de charrues à traction animale, voire de tracteurs, héritage de la dynamique cotonnière, est plus fréquente en zone Ouest (Raymond et Fok, 1995 ; DRED, 2003a,b) $)^{9}$. Les infrastructures routières et ferroviaires et l'existence d'un tissu industriel plus développé peuvent également favoriser la commercialisation en zone Ouest.

L'enquête qualitative menée auprès des producteurs nous renseigne sur les motivations des choix d'assolement au cours des cinq dernières années. Deux types de facteurs apparaissent. D'une part, des facteurs « techniques et sociaux» tels que le potentiel de production et le caractère autoconsommable des productions vivrières. D'autre part, des facteurs économiques

Figure 5. Répartition des cultures en zone Ouest et en Sissili en 2009

Figure 5a. Zone Ouest

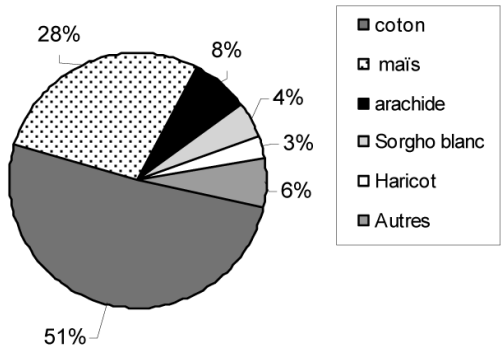

Figure 5b. Sissili

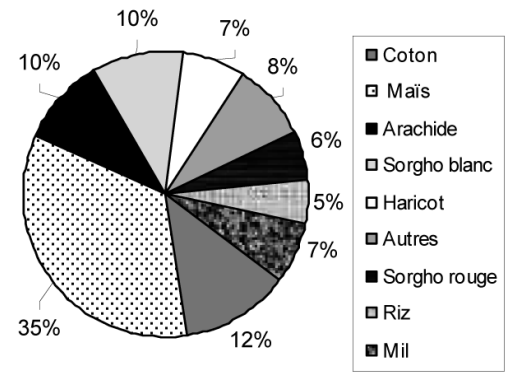

Source : les auteures

9. Raymond G., Fok M. (1995). Relation entre cotons et vivriers en Afrique de l'Ouest et du Centre. Le coton affame les populations : une fausse affirmation? Économies et Sociétés, Série Développement agro-alimentaire, p. 221-234 ; Direction Régionale de l'Économie et du Développement (DRED) des Hauts Bassins (2003a). Monographie de la province de la Comoé. Burkina Faso ; DRED des Hauts Bassins (2003b). Monographie de la province du Houet. Burkina Faso. 


\section{FAITS ET CHIFFRES}

liés au niveau des prix et à la sécurité des débouchés. Selon la zone, l'un des deux types de facteurs prédomine et oriente les choix d'assolement vers le maïs ou le coton. En zone Ouest, les facteurs économiques prédominants associés au coton expliquent le maintien de cette culture tandis qu'en Sissili, les facteurs sociaux liés aux cultures vivrières prédominent et guident l'orientation des producteurs vers les productions de maïs, sorgho rouge, sésame et soja. En zone Ouest, selon les producteurs, la tendance est au maintien de la production de coton afin d'assurer les débouchés. Toutefois, les producteurs diversifient de plus en plus, en intégrant davantage l'arachide et le riz. En Sissili, les producteurs se maintiennent dans une logique de diversification dans laquelle le maïs est prépondérant.

Tableau 1. Caractéristiques intrinsèques des zones de l'étude

\begin{tabular}{|c|c|c|}
\hline Variables & Zone Ouest : Houet et Comoé & Sissili \\
\hline Superficie totale & $27000 \mathrm{~km}^{2}$ & $7227 \mathrm{~km}^{2}$ \\
\hline Contraintes du milieu & \multicolumn{2}{|c|}{$\begin{array}{l}\text { Sols érosifs, carence en matière organique ; feux de brousse, pression anthro- } \\
\text { pique }\end{array}$} \\
\hline $\begin{array}{l}\text { Population } \\
\text { Croissance démographique }\end{array}$ & $\begin{array}{l}1600000 \text { hab. } \\
3,6 \% \text { et } 7 \% \text { pour Bobo Dioulasso (migration) }\end{array}$ & $\begin{array}{l}188000 \text { hab. } \\
2,6 \%\end{array}$ \\
\hline Équipement & $\begin{array}{l}\text { Charrues à tractions animales et un certain } \\
\text { nombre en tracteurs. }\end{array}$ & $\begin{array}{l}\text { Exploitations peu méca- } \\
\text { nisées }\end{array}$ \\
\hline Infrastructures & $\begin{array}{l}\text { Axe routier Niamey-Abidjan ; voie ferroviaire } \\
\text { Ouagadougou-Abidjan; Proximité du Mali, Côte } \\
\text { d'Ivoire }\end{array}$ & Proximité du Ghana \\
\hline Secteur industriel & $\begin{array}{l}\text { Comoé : Sucre, farine alcool- égrenage de coton- } \\
\text { scieries; Houet : industrie de l'alimentation } \\
\text { animale et transformation }\end{array}$ & Exploitation du bois \\
\hline
\end{tabular}

Source : DRED du Burkina Faso (2003a, b) ; Direction générale de l'économie et de la planification (2003)¹0.

Tableau 2. Chiffres d'affaires (moyenne par UPA)

\begin{tabular}{lllll}
\hline & & Ventes totales VT & CAv & CAm \\
\hline OUEST & & & \\
& Moyenne & 1303147 & 571597 & 288683 \\
& Écart-type & 1240087 & 617350 & 351372 \\
\hline \multirow{2}{*}{ SISSILI } & Ratios & & CAv/NT $=0,44$ & CAm/CAv $=0,50$ \\
& & & \\
& Moyenne & 830877 & 773867 & 308167 \\
& Écart-type & 552644 & 497158 & 303996 \\
\hline \multirow{2}{*}{ test } & Ratios & & CAv/NT $=0,93$ & CAm/CAv $=0,40$ \\
& t-stat & $-2,56$ & $-1,49$ & $-0,29$ \\
& p-value & 0,006 & 0,004 & 0,39 \\
\hline
\end{tabular}

Note : Pour le coton, I'analyse est basée sur la Marge après remboursement des intrants (MARI), donnée de revenu qui internalise une partie des coûts de production. Les ventes totales correspondent à la somme du chiffre d'affaires vivrier et de la MARI coton.

Source : les auteures.

10. Direction générale de l'économie et de la planification (2003). Monographie de la province de la Sissili. Burkina Faso. 
Répartition du chiffre d'affaires entre vivrier et coton

Le tableau 2 synthétise les données de chiffre d'affaires collectées lors des enquêtes. Il représente successivement les valeurs moyennes par UPA des ventes totales (VT), des chiffres d'affaires vivriers (CAv) et des chiffres d'affaires du maïs seul (CAm), selon les zones.

Le produit des ventes totales est significativement supérieur en zone Ouest au seuil de $5 \%$ tandis que le chiffre d'affaires vivrier (CAv) est statistiquement supérieur en Sissili. Pour le maïs, il n'y a en revanche pas de différence significative au niveau du chiffre d'affaires (CAm) par UPA entre les zones.

La comparaison des ratios montre que la part du vivrier dans le chiffre d'affaires total est de $93 \%$ en Sissili contre $44 \%$ en zone Ouest. La part du maïs dans le chiffre d'affaires vivrier est de $40 \%$ en Sissili contre $50 \%$ en zone Ouest. Le coton est donc le principal poste de vente en zone Ouest alors qu'il est marginal en Sissili. En zone Ouest, le maïs vient en seconde position après le coton dans les productions commercialisées. Ceci démontre bien l'existence et l'importance de la dynamique coton/maïs encouragée par les sociétés cotonnières dans cette zone. En Sissili, le maïs constitue le principal poste de vente avec des performances quasi similaires à celles de la zone Ouest. Ainsi, l'analyse du chiffre d'affaires confirme la prédominance du vivrier en Sissili contrairement à la zone Ouest où la place du coton est prédominante.

\section{Analyse et discussion}

En zone rurale d'Afrique subsaharienne, il est souvent admis que les revenus des exploitations familiales dépendent de leur dotation en facteurs de production à savoir main-d'œuvre familiale, équipement et cheptel (Devèze et Halley des Fontaines,
2005) ${ }^{11}$. À ces facteurs s'ajoute l'accès à la terre et aux consommations intermédiaires (engrais, semences, produits phytosanitaires). Afin de tester ces hypothèses, une analyse de corrélation par zone a été réalisée entre le chiffre d'affaires vivrier moyen des UPA d'une part et chacun des facteurs de production disponibles d'autre part (tableau 3).

Les deux zones présentent des similitudes concernant la superficie totale, le nombre de bœufs de labour possédés et le nombre de charrues. Ces facteurs d'équipement et de productivité du travail n'expliquent donc pas la différence constatée entre les deux zones au niveau des ventes vivrières.

En zone Ouest, le chiffre d'affaires vivrier présente une forte corrélation $(\geq 0.5)$ avec le coût de la main-d'œuvre salariée, le revenu coton et la taille du cheptel bovin. Ces trois paramètres étant directement liés à la culture de rente du coton, ce résultat met en évidence le lien de dépendance du système vivrier vis-à-vis du système coton en zone Ouest. En Sissili, la fertilisation à l'hectare (épandage de fumure et engrais céréales) et la possession d'ovins sont les principaux facteurs affichant une forte corrélation avec le chiffre d'affaires vivrier. Ces résultats suggèrent que l'orientation vers la production vivrière dépend principalement de l'accès à la fertilisation organique ou chimique pour la Sissili.

En définitive, le comportement des UPA vis-à-vis de l'utilisation de fumure organique est différent dans les deux zones : en zone Ouest, plus les UPA sont orientées vers le marché et bénéficient de revenus élevés, moins elles utilisent de fumure au profit des engrais chimiques. Ceci va de pair avec l'intensification liée à la culture

11. Devèze J.-C., Halley des Fontaines D. (2005). Le devenir des agricultures familiales des zones cotonnières africaines : une mutation à conduire avec tous les acteurs. AFD, $85 \mathrm{p}$. 
du coton pour ces UPA. Les UPA de la zone Ouest s'approvisionnent en engrais à $90 \%$ auprès de la SOFITEX alors que les engrais chimiques utilisés en Sissili viennent à $60 \%$ du marché. Ceci peut s'expliquer par les règles de la SOFITEX en matière d'attribution d'engrais coton destinés aux céréales : un système de péréquation visant à fournir à tous ses producteurs de coton des engrais coton et céréales au même prix quelle que soit leur situation géographique. Au contraire, la Sissili s'inscrit dans une dynamique visant sa propre autonomie en matière de fertilisation et elle n'affiche pas cette relation de dépendance à la filière coton pour les revenus et l'approvisionnement en engrais.

Deux types de stratégies différentes sont ainsi mis en œuvre par les producteurs des deux zones. En zone Ouest, les agriculteurs sont dans une logique de système de

Tableau 3. Corrélations entre ventes vivrières moyennes par UPA et facteurs productifs

\begin{tabular}{lcc}
\hline & $\begin{array}{c}\text { ZONE } \\
\text { OUEST }\end{array}$ & SISSILI \\
\hline Superficie totale & $0,47^{*}$ & $0,66^{*}$ \\
Superficie hors coton & & $0,60^{*}$ \\
Coût main-d'œuvre & $0,59 *$ & $0,33^{* *}$ \\
Coût main-d'œuvre/ha & $0,50^{*}$ & 0,12 \\
Bœufs de labour & $0,55^{*}$ & $0,42^{*}$ \\
Charrue & $0,44^{*}$ & $0,56^{*}$ \\
Bovins & $0,46^{*}$ & 0,05 \\
Ovins & 0,13 & $0,41^{*}$ \\
Fumure/ha & $-0,19$ & $0,43^{*}$ \\
Nombre sacs engrais chimiques/ & $-0,01$ & $0,45^{*}$ \\
ha hors coton & & \\
Revenu coton & $0,59 *$ & 0,30 \\
Nombre de sacs d'engrais coton & $0,34 *$ & 0,04 \\
Superficie en coton & $0,33^{* *}$ & 0,30 \\
Nombre d'animaux & 0,31 & $0,37^{* *}$ \\
Caprins & 0,25 & $0,33^{*}$ \\
Coût engrais céréales/ha & $\mathrm{nc}$ & $0,44^{*}$ \\
Main-d'œuvre familiale/ha & $-0,28$ & $-0,35^{*}$ \\
\hline
\end{tabular}

Note: ${ }^{*}{ }^{*}{ }^{*}$ significativité à 5 et $10 \%$.

Source : les auteures. culture intensif coton/vivrier. Ils sont plutôt consommateurs d'engrais chimiques, mieux dotés en facteurs de production et plus orientés vers le marché et les cultures de rente. Ils sont également plus fragiles puisque $50 \%$ de leur assolement est destiné au coton. Leur stratégie consiste à maintenir ce lien au système coton qui leur assure un débouché malgré un prix bas tout en se diversifiant vers des cultures de rente telles que l'arachide, le maïs ou le riz. Le maïs est en outre encouragé par la SOFITEX et l'UNPCB. En Sissili, plus éloignée de la zone coton, la rotation et la diversification des cultures semblent plus intégrées dans les pratiques agricoles. Compte tenu du manque de moyens techniques, les performances affichées restent fragiles.

$$
\begin{gathered}
* \\
* *
\end{gathered}
$$

Ce travail vise à identifier les facteurs de développement pour deux cultures, le coton et le maïs, dans deux zones du Burkina Faso, la zone Ouest et la Sissili, à partir d'enquêtes menées auprès de 98 exploitations agricoles. Globalement, la place du maïs dans la production nationale est en progression. Malgré l'instabilité des prix du maïs sur le marché, sa culture a un fort potentiel de production et représente respectivement $30 \%$ et $40 \%$ de l'assolement en zone Ouest et en Sissili. La culture du coton confère un revenu fixe, quoique modeste, et dès lors qu'ils ne produisent pas à perte, les producteurs de la zone Ouest poursuivent cette culture. Les infrastructures mises en place pour commercialiser le coton profitent aux autres cultures. Plus que la substitution du maïs au coton, un développement concomitant est observé en zone Ouest, le maïs bénéficiant des structures du système coton. De plus, l'appareil de production hérité du système coton (possession de charrues à traction animale, voire de tracteurs) contribue favorablement à l'amélioration des rendements du maïs en zone Ouest. Les producteurs de Sissili 
intègrent largement le maïs dans leur assolement et diversifient leurs cultures. Leurs ventes reposent principalement sur les productions vivrières (dont $40 \%$ sont représentées par le maiis), sécurisantes du fait de leur caractère consommable et de leur diversité face au risque. Le potentiel de production et de vente de ces cultures repose pour beaucoup sur l'accès à la fumure organique et aux engrais.

Face à l'instabilité du marché des produits agricoles, en l'absence de régulation par les pouvoirs politiques et de filets de sécurité, les enquêtes ont montré que, selon les contextes, les producteurs limitent leurs risques et s'adaptent aux changements en modulant leurs assolements et leurs modes de culture. Pour accroître notamment leurs rendements et la compétitivité, un meilleur accès à l'information, aux engrais, aux équipements est requis. À ce stade, l'enquête ne permet pas de conclure à une marche vers la substitution du coton par le maïs ni même à établir une tendance pour l'avenir. Une étude sur plusieurs années serait nécessaire.

L'Afrique de l'Ouest est impliquée dans les règles du commerce régional et dans la gestion des stocks. Le niveau étatique a un rôle à jouer sur l'accès à l'investissement agricole, aux infrastructures, sur la gestion de la volatilité des prix, dans la recherche agronomique et la formation.
Afin de limiter le secteur informel, l'État devrait faciliter la création d'un cadre légal adéquat aux commerçants et renforcer le système bancaire. D'après Ouadraego et al. $(2011)^{12}$, le Burkina Faso dispose d'un avantage comparatif pour la production de maïs. Ceci s'explique notamment par la grande disponibilité en facteurs domestiques ainsi que par les subventions mises en place par l'État pour le développement de la filière depuis 2008. Le paysan en système traditionnel (non irrigué et non mécanisé) perçoit un revenu inférieur au niveau du seuil de pauvreté. Selon les auteurs, cet avantage comparatif sera amélioré si les agriculteurs augmentent les rendements grâce à une meilleure gestion de l'itinéraire technique. La question de la durabilité du système maïs, culture ayant des besoins en eau importants, n'est pas remise en cause.

Les auteurs remercient tout particulièrement Didier Simon et Marie-Cécile Thirion de l'Agence Française du Développement (AFD), Nicolas Bricas du CIRAD ainsi que l'éditeur et les relecteurs anonymes qui ont permis d'améliorer ce papier. Les auteurs remercient aussi les personnes ayant contribué à la réalisation de cette étude par leur témoignage et leur appui lors de la mission terrain : I'Agence de Ouagadougou $(A F D)$, les responsables de I'UNPCB et de la FEPPASI en particulier. Les conclusions émises sont toutefois propres aux auteures.

12. Ouedraogo M., Ouedraogo S., Kabore M. (2011). Analyse de la compétitivité de la filière maïs au Burkina Faso, PRESAO, rapport final n³-2011-12. 


\section{ANNEXES}

\section{Description de l'enquête et échantillonnage}

La première partie des enquêtes menées en juin 2009 porte sur des données quantitatives relatives aux ventes vivrières et aux caractéristiques des 98 UPA. La seconde partie concerne des données qualitatives relatives à la perception des producteurs de leur environnement et de leurs performances de production et commercialisation. Le tableau 1A présente le plan d'échantillonnage.

En zone Ouest, avec l'appui du responsable de la commercialisation de l'UNPCB, cinq villages ont été choisis en fonction de la distance au marché et de la participation à l'opération pilote de commercialisation du maïs conduite par l'UNPCB en 2008.

Au sein des villages, les Groupements de producteurs de coton (GPC) ont été choisis selon un critère de dynamisme traduisant les niveaux de rendement en coton/maïs et le degré d'implication dans les opérations initiées par l'UNPCB. Ainsi, pour chaque village, un GPC dynamique et un GPC « moins dynamique » ont été choisis. En Sissili, le choix des départements et villages a été effectué en fonction de l'ancienneté de leur adhésion à la FEPPASI. Dans les deux zones, le choix des UPA a été fait en fonction de leur taille et de leur niveau de revenu de sorte qu'elles soient représentatives de la distribution au sein du groupement. Pour des raisons techniques, une exploitation n'a pas pu être enquêtée à l'Ouest et le nombre d'exploitations enquêtées en Sissili diffère selon les villages. Le tableau $2 A$ synthétise les principales caractéristiques des deux zones retenues dans le cadre de l'enquête. Le tableau $3 A$ présente une synthèse des résultats à travers la dotation des UPA en facteurs de production, leur utilisation d'engrais et leurs performances de production et de vente. Des tests statistiques de comparaison de moyennes (tests de Student) ont été réalisés d'après les résultats d'enquêtes.

Tableau 1A. Plan d'échantillonnage de l'étude

\begin{tabular}{|c|c|c|c|c|c|}
\hline Zone & $\begin{array}{c}\text { Région } \\
\text { (province) }\end{array}$ & Département & Village & $\begin{array}{c}\text { Groupement de } \\
\text { producteurs coton (GPC) }\end{array}$ & $\begin{array}{l}\text { Nombre } \\
\text { d'UPA }\end{array}$ \\
\hline \multirow[b]{2}{*}{ OUEST } & \multirow{2}{*}{$\begin{array}{l}\text { Hauts } \\
\text { Bassins } \\
\text { (Houet) }\end{array}$} & Bama & Séguéré & Sekoura & 12 \\
\hline & & Bobo Dioulasso & Koro & \begin{tabular}{|l} 
Signignasigui \\
Badala aladaré
\end{tabular} & $\begin{array}{l}6 \\
6 \\
\end{array}$ \\
\hline \multirow{3}{*}{ OUEST } & \multirow{3}{*}{$\begin{array}{l}\text { Cascades } \\
\text { (Comoé) }\end{array}$} & Tiéfora & $\begin{array}{l}\text { Dramandougou } \\
\text { (26 GPC) }\end{array}$ & Mimaloman Sababouagnouma & $\begin{array}{l}6 \\
6\end{array}$ \\
\hline & & Sidéradougou & Dégué Dégué & Faso Jigui & 11 \\
\hline & & & Yadé (7 GPC) & $\begin{array}{l}\text { Benkadi } \\
\text { Diato }\end{array}$ & $\begin{array}{l}6 \\
6 \\
\end{array}$ \\
\hline \multicolumn{6}{|c|}{ Sous-total } \\
\hline \multirow{3}{*}{ SISSILI } & \multirow{3}{*}{$\begin{array}{l}\text { Centre } \\
\text { Ouest } \\
\text { (Sissili) }\end{array}$} & Tô & Métio & & 11 \\
\hline & & Boura & $\begin{array}{l}\text { Boura } \\
\text { Yoro }\end{array}$ & & $\begin{array}{l}8 \\
6 \\
\end{array}$ \\
\hline & & Léo & $\begin{array}{l}\text { Nadion } \\
\text { Kayéro } \\
\text { Léo }\end{array}$ & & $\begin{array}{l}4 \\
6 \\
4 \\
\end{array}$ \\
\hline \multicolumn{6}{|c|}{ Sous-total } \\
\hline & & & & TOTAL & 98 \\
\hline
\end{tabular}

Source : les auteures. 


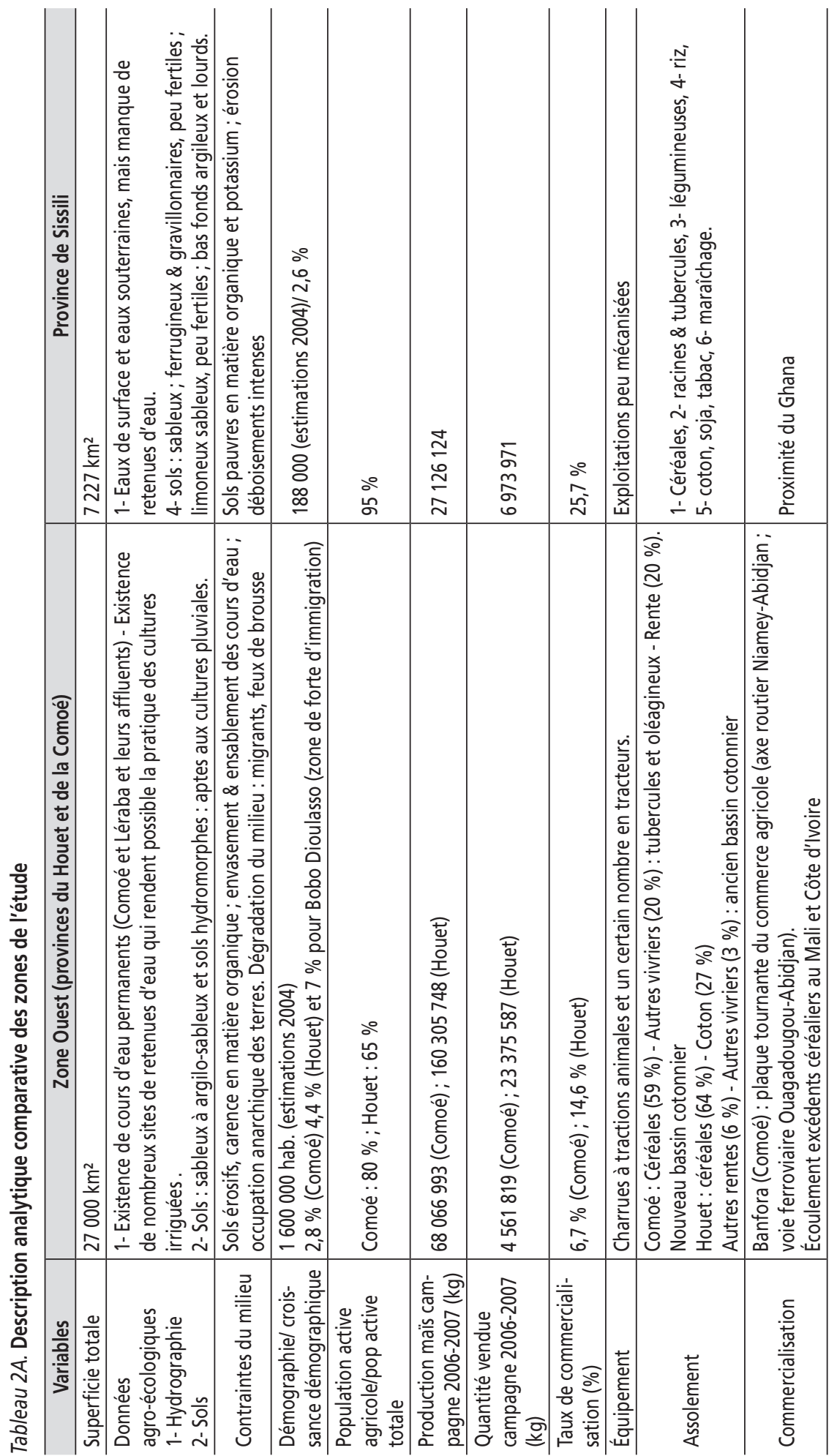


FAITS ET CHIFFRES

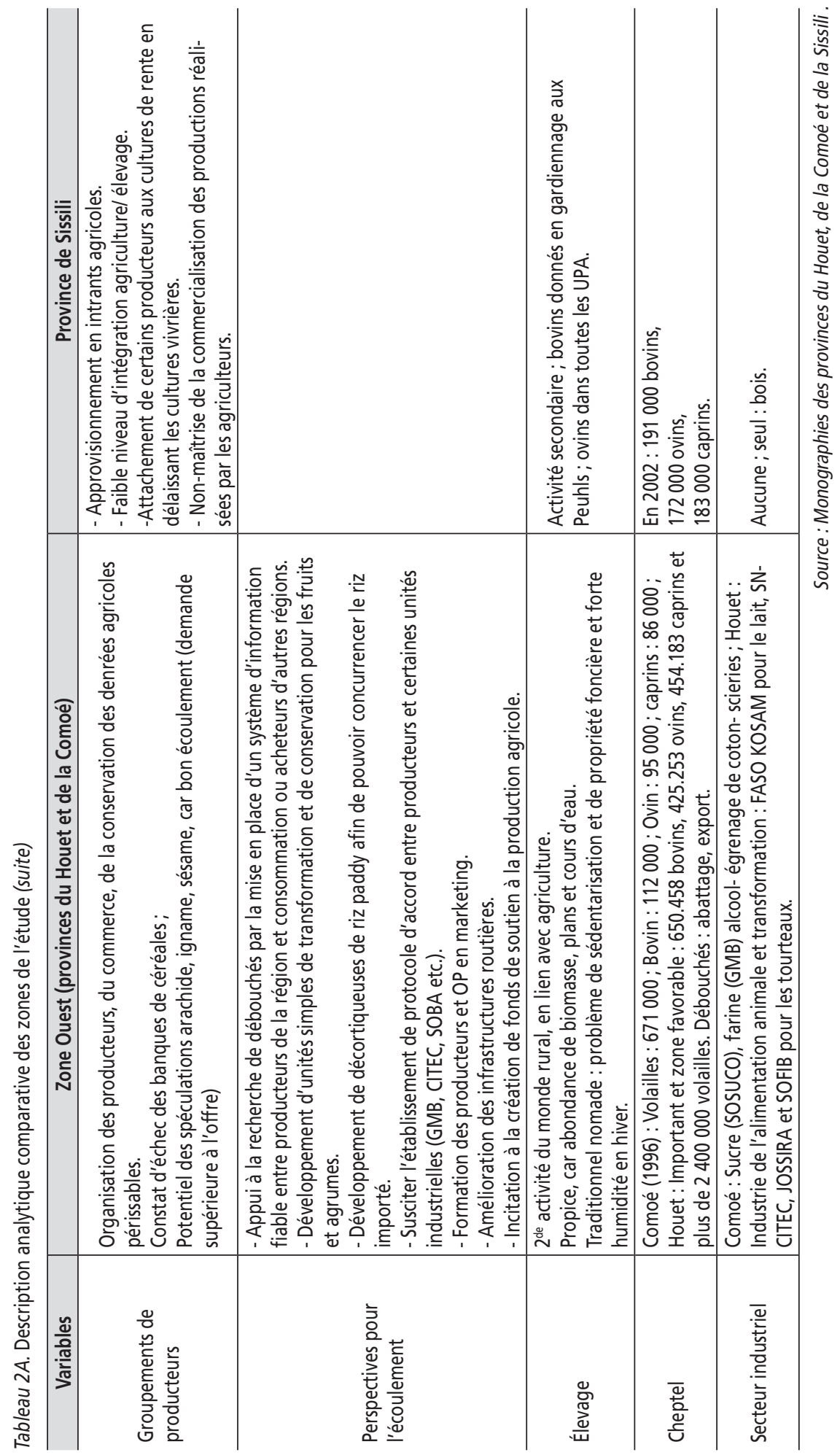

118 • Économie Rurale 341/Mal-Juin 2014 
FAITS ET CHIFFRES

Tableau 3A. Structure des UPA selon la zone d'étudeSource : Les auteures d'après enquêtes.

\begin{tabular}{|c|c|c|c|c|}
\hline \multirow{2}{*}{ Variables } & \multicolumn{2}{|c|}{ Moyennes/UPA } & \multirow{2}{*}{ t-ratio } & \multirow{2}{*}{ p-value } \\
\hline & Zone Ouest & Sissili & & \\
\hline \multicolumn{5}{|c|}{ TERRE } \\
\hline Surface agricole utile (SAU) (ha) & 11,7 & 7,8 & 3,73 & 0,00 \\
\hline \multicolumn{5}{|l|}{ TRAVAIL } \\
\hline Main-d'œuvre familiale (pers) (MOF) & 5,6 & 4,8 & $-1,27$ & 0,20 \\
\hline MOF/ha (pers/ha) & 0,54 & 0,71 & 2,4 & 0,02 \\
\hline Coût de la MO salariée (FCFA) & 63407 & 84731 & 1,18 & 0,24 \\
\hline Coût de la MOS/ha (FCFA/ha) & 4813 & 12140 & 3,58 & 0,00 \\
\hline \multicolumn{5}{|c|}{ CAPITAL } \\
\hline Nombre de bœufs de labour & 3,6 & 2,9 & 1,48 & 0,14 \\
\hline Nombre de charrues & 1,5 & 1,7 & $-1,03$ & 0,31 \\
\hline Nombre de bovins & 5,9 & 4,8 & 0,55 & 0,58 \\
\hline Nombre d'ovins & 9,6 & 15,9 & $-2,09$ & 0,04 \\
\hline Nombre de caprins & 4,3 & 11,9 & 3,06 & 0,00 \\
\hline \multicolumn{5}{|c|}{ FERTILISATION } \\
\hline Fumure organique (charrettes/ha) & 2,4 & 5,4 & $-3,27$ & 0,00 \\
\hline $\begin{array}{l}\text { Engrais chimique/ha hors coton } \\
\text { (nombre de sacs/ha) }\end{array}$ & 1,8 & 1,3 & 2,25 & 0,02 \\
\hline $\begin{array}{l}\text { Sacs d'engrais chimiques SOFITEX } \\
\text { destinés au coton }\end{array}$ & 19 & 2,3 & $-7,15$ & 0,00 \\
\hline $\begin{array}{l}\text { Sacs d'engrais chimiques SOFITEX } \\
\text { destinés aux céréales }\end{array}$ & 9 & 3,3 & $-4,33$ & 0,00 \\
\hline $\begin{array}{l}\text { Sacs d'engrais chimiques du marché } \\
\text { destinés aux céréales }\end{array}$ & 0,8 & 6 & 3,95 & 0,00 \\
\hline \multicolumn{5}{|c|}{ PERFORMANCES } \\
\hline Production vivrière (kg/an) & 7398 & 9318 & $-2,18$ & 0,03 \\
\hline Commercialisation vivrière (kg/an) & 4211 & 5325 & $-1,45$ & 0,15 \\
\hline Taux de commercialisation (\%) & 57 & 57 & - & - \\
\hline Montant des ventes vivrières (FCFA) & 571596 & 773867 & $-1,76$ & 0,08 \\
\hline MARI coton & 711941 & 79423 & 6,19 & 0,00 \\
\hline Marge brute totale & 1059722 & 601569 & 2,84 & 0,00 \\
\hline Marge brute /ha & 85073 & 78955 & 0,45 & 0,65 \\
\hline
\end{tabular}

Note : La Marge après remboursement des intrants (MARI) correspond à la somme perçue par le producteur de coton de la part de la SOFITEX après déduction du coût des intrants qu'il a obtenus à crédit en début de campagne. II s'agit d'une donnée de revenu. La marge brute totale est calculée de la façon suivante : valeur des productions végétales vendues - intrants - salaire des ouvriers agricoles - location de terres. 